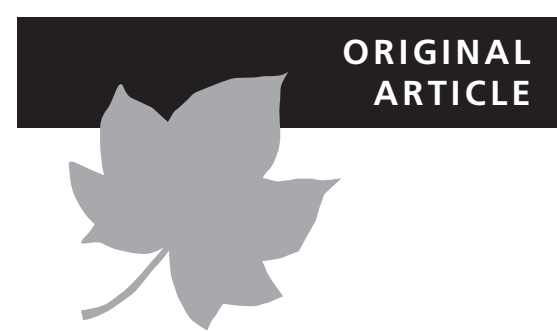

\title{
A similar phylogeographical structure among sympatric North American birches (Betula) is better explained by introgression than by shared biogeographical history
}

\author{
Ashley M. Thomson ${ }^{1,2 *}$, Christopher W. Dick ${ }^{2}$ and Selvadurai
}

Dayanandan $^{1}$

${ }^{1}$ Québec Centre for Biodiversity Science, Montréal and Department of Biology and Centre for Structural and Functional Genomics, Concordia University, Montreal, Quebec H4B 1R6, Canada, ${ }^{2}$ Department of Ecology and Evolutionary Biology, University of Michigan, Ann Arbor, MI 48109-1048, USA

${ }^{*}$ Correspondence: A. M. Thomson, Department of Ecology and Evolutionary Biology, University of Michigan, 830 North University, Ann Arbor, MI 48109-1048, USA. E-mail: amthoms@umich.edu

\begin{abstract}
Aim A comparative analysis of the chloroplast (cp) DNA structure of eastern North American birches (Betula) was undertaken to infer the impacts of Quaternary climate change on the phylogeographical structure of these species.
\end{abstract}

Location Eastern North America.

Methods Genetic variation in chloroplast microsatellites (cpSSRs) and the psbA-trn $\mathrm{H}$ intergenic spacer in Betula papyrifera, Betula alleghaniensis and Betula lenta was analysed in samples from 65, 80 and 12 populations, respectively. Co-occurring Betula uber, Betula populifolia and Betula cordifolia were also sampled to examine haplotype relationships and account for potential introgression. Haplotype networks, Bayesian analysis and comparisons of $R_{\mathrm{ST}}$ and $G_{\mathrm{ST}}$ values were used to evaluate the phylogeographical structure. Genetic diversity within and among species was compared using rarefaction analysis.

Results The two most widespread species, B. papyrifera and B. alleghaniensis, showed high levels of haplotype diversity, while the Appalachian endemic $B$. lenta possessed a single haplotype. Bayesian analysis revealed three main phylogeographical groups for B. papyrifera and four groups for B. alleghaniensis, and these two species showed extensive regional haplotype sharing and a high introgression ratio.

Main conclusions We postulate that at least three separate refugia contributed to the recolonization of $B$. papyrifera and $B$. alleghaniensis within eastern North America, while $B$. lenta appears to have recolonized from a single refugium. A high haplotype diversity of $B$. papyrifera and $B$. alleghaniensis in the Great Lakes region may reflect biogeographical contact between eastern and western lineages, with the potential influence of periglacial refugia. Similar phylogeographical patterns in the distantly related $B$. papyrifera and B. alleghaniensis represent a geographical turnover of the same locally shared haplotypes, pointing to introgression rather than shared biogeographical history as the mechanism. Although similar phylogeographical patterns are often interpreted as evidence for common biogeographical histories, our study demonstrates that such patterns can also arise through introgression.

\section{Keywords}

Betula, birches, comparative phylogeography, chloroplast DNA, eastern North America, haplotype-sharing, hybridization, introgression, Quaternary climate change, refugia. 


\section{INTRODUCTION}

The genetic structure and diversity of temperate plant species are strongly influenced by vegetation changes associated with Quaternary glacial-interglacial cycles (Hewitt, 2000). The prevalent view is that unfavourable climatic conditions and habitat loss as a result of advancing ice sheets, particularly during the Last Glacial Maximum (LGM), truncated geographical ranges of species in the Northern Hemisphere and forced many temperate tree species to retreat to southern refugial locations (Bennett et al., 1991; Taberlet et al., 1998; Stewart et al., 2010). As a result of long-term genetic isolation, different refugial populations are expected to have diverged from one another (Petit et al., 2003a) and display a northwards decline in genetic diversity associated with founder events during recolonization (Hewitt, 2000). However, recent studies have provided evidence that this classical viewpoint may be overly simplistic, with species demonstrating complex and often individualistic geographical responses to past climatic fluctuations (Stewart et al., 2010). For example, a number of European angiosperms possess a higher diversity at intermediate latitudes than at southern latitudes, presumably as a result of the mixing of lineages in refugial contact zones (see Petit et al., 2003a, for a review). Moreover, increasing numbers of studies are reporting high genetic diversity or endemic haplotypes at relatively high northern latitudes, suggesting that numerous temperate plant species may have persisted within periglacial or cryptic northern refugia (Willis et al., 2000; Stewart \& Lister, 2001; Parducci et al., 2012).

Comparative phylogeographical studies have been widely used to examine regional biogeography and infer the geographical distribution of evolutionary lineages, by comparing patterns of genetic variation among co-distributed taxa. While some such studies reveal concordant biogeographical patterns among closely related tree species (e.g. Premoli et al., 2012), others reveal idiosyncratic patterns attributable to differing LGM distribution patterns or post-glacial recolonization dynamics (e.g. Heuertz et al., 2006). A study of European birches, for example, revealed a greater number of demes within Betula pubescens compared with Betula pendula, which was attributed to the survival and earlier recolonization of $B$. pubescens at higher latitudes during the last glacial period (Maliouchenko et al., 2007). Furthermore, comparative phylogeographical studies of closely related species often reveal introgression in the form of localized haplotype sharing, as has been documented in European Quercus (Petit et al., 1993; Belahbib et al., 2001). Such introgression can potentially alter species haplotype distributions through the introduction of novel haplotype variation, and should be accounted for when drawing inferences about species' biogeographical histories; for example, the finding of a distinct phylogeographical group for Acer rubrum in the lower Mississippi River Valley is best explained by introgression of haplotypes from Acer saccharinum rather than by historical biogeographical contingencies (Saeki et al., 2011). To date, most comparative phylogeographical studies of North American trees have focused on widespread boreal conifers or trees of unglaciated regions (e.g. Soltis et al., 2006; JaramilloCorrea et al., 2009) and there is a need for further comparative studies to understand better the glacial history of the cold-temperate angiosperms of eastern North America (but see Saeki et al., 2011).

North American birches (Betula) are ideal for studies of comparative post-glacial biogeography. Betula comprises approximately 17 species in eastern North America, which share traits related to reproduction and dispersal but differ in their climatic tolerances and habitat preferences (Furlow, 1990). This study examined the phylogeography and glacial history of three Betula species of eastern North America: Betula papyrifera Marshall (paper birch), Betula alleghaniensis Britton (yellow birch) and Betula lenta L. (sweet birch). In addition, we sampled the less common species Betula populifolia Marshall, Betula cordifolia Regel and Betula uber (Ashe) Fernald to obtain a complete community-level sampling of Betula and account for potential introgression.

Betula papyrifera is the most widely distributed and coldtolerant of the North American birches, with a distribution ranging from the boreal forest region of the USA and Canada to the northern limit of tree growth (Safford et al., 1990). In comparison, B. alleghaniensis has a more southern distribution, occupying temperate forests from south-eastern Canada to New England and the southern Appalachians in the USA (Erdmann, 1990). Betula lenta is endemic to the Appalachian region of the eastern USA; it occurs from southern Maine to northern Alabama and Georgia (Lamson, 1990). Betula populifolia is confined to eastern Canada and the north-eastern USA, ranging from New Brunswick and Nova Scotia to Delaware, northern Pennsylvania and eastern Ontario (Furlow, 1997). Betula cordifolia occurs at elevations of 800-2000 m in the Canadian Maritimes and New England to Pennsylvania, North Carolina, Quebec, central Ontario, Minnesota and Michigan. Betula uber is represented by a single known population in south-west Virginia. A comparative summary of selected ecological and morphological characteristics of the six eastern North American Betula species examined here is presented in Appendix S1. The study species fall into the subgenera Betulenta, which contains species with generally dark, non-exfoliating bark (including B. alleghaniensis, B. lenta and B. uber), and Betula, which contains the white-barked birches (including B. papyrifera, B. populifolia and B. cordifolia) (DeJong, 1993). This morphological classification is supported by molecular studies that separate the white- and dark-barked birches into different clades (Jarvinen et al., 2004; Li et al., 2005; Schenk et al., 2008).

Palaeobotanical reconstructions indicate the occurrence of two refugial Betula populations in eastern North America at the time of the LGM (c. $26.5 \mathrm{ka}-19 \mathrm{ka}$ ), occupying regions of the mid-Atlantic coastal plain and north-central Louisiana (Delcourt \& Delcourt, 1987; Jackson et al., 1997). A third population appeared later, between 15 and $14 \mathrm{ka}$, in the American Midwest region. Starting around $18 \mathrm{ka}$, the 
Atlantic coastal population began to expand westwards and southwards until it coalesced with the Midwest and Louisiana populations. From there, Betula populations expanded northwards following the retreat of the ice sheet. More detailed information regarding species-specific distributions has been obtained from macrofossils documenting the occurrence of $B$. papyrifera in northern Georgia at the time of the LGM. In contrast, $B$. alleghaniensis macrofossils are absent from all sites until its first appearance at 9 ka in New Hampshire (Jackson et al., 2000)

We sampled chloroplast DNA (cpDNA) markers from our study taxa from across eastern North America. Our specific objectives were: (1) to examine patterns of cpDNA variation to test for individualistic or shared patterns of phylogeographical structure in Betula; (2) to combine genetic and fossil evidence to infer the LGM distribution and post-glacial recolonization routes for Betula; and (3) to explore the potential effects of historical species interactions, such as hybridization and introgression (sensu Saeki et al., 2011), on the phylogeographical patterns.

\section{MATERIALS AND METHODS}

\section{Population sampling}

Leaf samples for DNA analyses were obtained from 1-10 individuals per species where present in each of 36 natural populations located throughout eastern Canada and the USA. Individuals separated by at least $50 \mathrm{~m}$ were sampled. Leaf tissue was dried in silica gel in the field. Additional samples were obtained from the seed collections of the Canadian National Tree Seed Centre (CTNSC) (Fredericton, Canada) and the British Columbia Tree Seed Centre (BCTSC) (Surrey, Canada). The seed collections spanned 75 localities, with B. papyrifera from 42 sites, B. alleghaniensis from 17 sites, B. populifolia from 10 sites and B. cordifolia from 10 sites. Because the seed collections consisted of a mix of single-tree and bulked seed, only a single seed per seed lot was used, in order to avoid genotyping multiple individuals from the same maternal tree. We also collected vegetative buds from a single individual of each of 36 provenances of $B$. alleghaniensis from a provenance trial located at the Kellogg Experimental Forest of Michigan State University (near Kellogg, MI, USA). In summary, the samples for this study represented 754 individuals from 123 populations of Betula from eastern North America and an additional 21 single-tree samples from the western distribution of B. papyrifera in British Columbia, Canada. Additional locality, sampling and voucher details are presented in Appendix S2.

\section{Laboratory procedures}

DNA was extracted from mature leaf tissues using the modified cetyltrimethylammonium bromide (CTAB) protocol of Zeng et al. (2002). Qiagen DNeasy extraction kits (Qiagen Inc., Valencia, CA) were used to extract DNA from vegetative buds and germinated seeds. The polymerase chain reaction (PCR) conditions and cpDNA primers used in this study are provided in Appendix S3. Haplotype variation was assessed using six chloroplast microsatellite (cpSSR) markers and the $p s b \mathrm{~A}-t r n \mathrm{H}$ intergenic spacer region. Three cpSSRs were developed for Betula in this study, while the remainder were obtained from the literature (Weising \& Gardner, 1999). Amplification of the $p s b \mathrm{~A}-t r n \mathrm{H}$ spacer region was conducted using the primers of Sang et al. (1997), and PCR products were sequenced using an Applied Biosystems 3730xl DNA Analyzer (Life Technologies, Grand Island, NY, USA) Sequence chromatograms were edited and aligned using Geneious 4.8 software (Biomatters Ltd, Auckland, New Zealand). Indels were coded as single characters. We used a reduced within-population sampling intensity for sequencing compared with cpSSR genotyping because initial range-wide screening revealed that haplotypes were generally fixed across broad spatial scales. Individuals from all singleton populations were sequenced, while for multi-individual populations an average of three individuals per population was sequenced.

\section{Data analyses}

Haplotypes were defined as unique combinations of allele variants of the cpSSR and $p s b \mathrm{~A}-t r n \mathrm{H}$ sequence data. Mutational relationships among the haplotypes were inferred with a statistical parsimony network using the program TCS 1.21 (Clement et al., 2000). Gaps were treated as the fifth state and the connection limit was set at eight steps. Haplotype frequencies were calculated using GenAlEx 6.41 (Peakall \& Smouse, 2006) and haplotype distribution maps were constructed using ArcGIS 10.0 (ESRI, Redlands, CA, USA).

Estimates of standardized cpSSR haplotype richness were obtained for each species after rarefaction to the minimum sample size of $n=16$ for B. cordifolia using CONTRIB 1.02 (Petit et al., 1998). Betula uber was excluded from the analysis because of its small sample size $(n=10)$ and because it possessed only one haplotype (see Results). A second calculation was made including only B. papyrifera and B. alleghaniensis with rarefaction to the minimum sample size of $n=240$ in B. papyrifera. For these analyses, far western populations of $B$. papyrifera were excluded so that haplotype richness estimates included only eastern North American populations of each species. We also estimated standardized cpSSR haplotype richness for individual populations of $B$. papyrifera and B. alleghaniensis, considering only those populations with at least three sampled individuals. Haplotype richness values for each population were then mapped and interpolated using ArcGIS to visualize geographical patterns of cPSSR haplotype diversity within species.

Analysis of molecular variance (AMOVA) was used for assessing the partitioning cpSSR haplotype variation as implemented in ArLequin 3.1 (Excoffier et al., 2005), treating each species individually as well as in species groupings. Only those populations with three or more sampled 
individuals were considered (B. papyrifera, $n=26$ populations; B. alleghaniensis, $n=29$ populations; B. lenta, $n=12$ populations) and the significance of the variance partitioning was calculated based on 10,000 random permutations of the data. We also tested for the presence of a phylogeographical structure of the cPSSR dataset by comparing permutated values of $R_{\mathrm{ST}}$ (synonymous with $N_{\mathrm{ST}}$ for microsatellite data) and $G_{\text {ST }}$ using the program PermutCpSSR 2.0 (Pons \& Petit, 1996), again considering only those populations with a minimum of three samples. To identify geographical patterns of genetic discontinuities, the population genetic structure for each species was examined using the Bayesian clustering approach implemented in BAPs software (Corander et al., $2003,2004)$. We conducted two separate sets of analyses in BAPS, first using the 'spatial clustering of groups' module, which considers the spatial location of populations in the determination of group structure, and second using the 'clustering of groups of individuals' module, which does not consider the geographical locations of populations. The model was run using the 'fixed $\mathrm{K}$ clustering' option, with individual values of $K$ ranging from 1 to 10 and 20 replicates for each value of $K$. The solution that produced the highest log likelihood was selected as optimal. Corresponding among-group variation components ( $F_{\mathrm{CT}}$ values) were calculated for the optimal BAPs groupings using AMOVA analysis in ARLEQuin software.

To examine the incidence of haplotype sharing between $B$. papyrifera and $B$. alleghaniensis, we calculated the introgression ratio (IG) (Belahbib et al., 2001) and modified introgression ratio $\left(\mathrm{IG}^{*}\right)$ (Thórsson et al., 2010), which quantify the similarity of haplotype compositions among species at sites where they co-occur. We also compared introgression ratios calculated for pairs of populations of the same species at different sites to introgression ratios calculated between two species at shared sites (IGR) (Palme et al., 2004). While IG and $\mathrm{IG}^{\star}$ do not distinguish whether haplotype sharing is the result of shared ancestry or introgression, significant negative correlations between IGR and geographical distance indicate the presence of isolation-by-distance resulting from local admixture. The significance of the correlations between IGR and geographical distance was tested using Mantel tests with 1000 permutations of the data. All statistical tests were conducted using R software (R Core Team, 2012). Haplotype sharing was not examined among other species because analyses showed that either they did not share haplotypes or because sample sizes were insufficient.

\section{RESULTS}

\section{Haplotype distributions}

The combined cpSSR and psbA-trn $\mathrm{H}$ sequence polymorphisms revealed 30 cpDNA haplotypes for the six North American Betula species (Fig. 1a). Haplotype definitions are presented in Appendix S3. In B. papyrifera, most of the eastern range, from central Ontario to New England and the
Maritimes, was dominated by $\mathrm{H} 8, \mathrm{H} 10$ and related haplotypes (Fig. 1b). A second group composed of H17 and H19 was found along the Atlantic coast of Canada. Betula papyrifera populations in western Ontario and the Great Lakes states contained a mixture of endemic H22, H29 and related haplotypes, as well as a low frequency of eastern haplotypes (H8 and related haplotypes). Haplotypes H20, H24 and H25 were common in southern British Columbia, while H27 was common in northern British Columbia. The remaining haplotypes ( $\mathrm{H} 1, \mathrm{H} 3, \mathrm{H} 7, \mathrm{H} 11, \mathrm{H} 26, \mathrm{H} 28$ and $\mathrm{H} 30)$ were unique to single individuals.

Of 14 haplotypes recovered for $B$. alleghaniensis, eight were shared with B. papyrifera and had similar geographical distributions (Fig. 1c). Haplotypes H8, H10, H14 and related formed a large eastern group. H17 and H19 occurred along the Atlantic coast. Populations west of the Great Lakes were composed predominantly of $\mathrm{H} 22$ and $\mathrm{H} 29$, and $\mathrm{H} 8$ at a lower frequency. In, B. alleghaniensis, the cpDNA haplotype distribution revealed a separate southern Appalachian haplotype group ( $\mathrm{H} 9$ and $\mathrm{H} 15)$ that was not evident in B. papyrifera. Haplotypes H4, H5, H16, H18 and H19 were unique to single individuals. The haplotype distribution for B. lenta differed from that of B. papyrifera and B. alleghaniensis, as a single haplotype (H23) was found throughout its geographical range (Fig. 1d). CpSSR haplotype distributions for $B$. populifolia and B. cordifolia (Fig. 1e,f) were similar to those of sympatric B. papyrifera and B. alleghaniensis, with populations composed mostly of H8, H10 and closely related haplotypes. Betula uber (Fig. 1g) was fixed for the single haplotype (H23) that was found in B. lenta.

Eight of the 20 haplotypes found in B. papyrifera were shared with $B$. alleghaniensis, while four of the six haplotypes found in B. populifolia were shared with B. papyrifera and $B$. alleghaniensis, and two of the three haplotypes found in $B$. cordifolia were shared with B. papyrifera and B. alleghaniensis. Generally, the shared haplotypes had similar geographical distributions within the species in which they occurred; H8 and $\mathrm{H} 10$ were shared within the eastern study area, while $\mathrm{H} 22$ and $\mathrm{H} 29$ were shared within the western Great Lakes region, H6 and H14 within the central-eastern Great Lakes region, and $\mathrm{H} 17$ and $\mathrm{H} 19$ within the Atlantic coastal region.

\section{Chloroplast DNA diversity}

Standardized estimates after rarefaction $(n=16)$ revealed that cpSSR haplotype richness was similar for B. papyrifera (3.37) and B. alleghaniensis (3.33), and lower for B. populifolia (2.61) and B. cordifolia (1.00). Allelic richness for B. lenta was 0.00 because it possessed only one haplotype. When only eastern North American populations of B. papyrifera and $B$. alleghaniensis were considered, rarefaction analysis $(n=240)$ revealed a slightly higher haplotype richness for $B$. papyrifera (9.00) than B. alleghaniensis (7.46). Estimates of haplotype diversity were similar for B. papyrifera and B. alleghaniensis, with values of 0.61 and 0.60 , respectively. Interpolated maps of cpSSR haplotype richness for B. papyrifera and $B$. 
Figure 1 (a) Statistical parsimony network of 30 chloroplast (cp) DNA haplotypes from North American populations of Betula species. Coloured circles represent the observed haplotypes and the size of the circles is proportional to the haplotype frequency. Black ellipses on lines connecting haplotypes represent inferred haplotypes. The geographical distribution of cpDNA haplotypes was recovered for (b) $B$. papyrifera, (c) B. alleghaniensis, (d) B. lenta, (e) B. populifolia, (f) B. cordifolia and (g) B. uber.
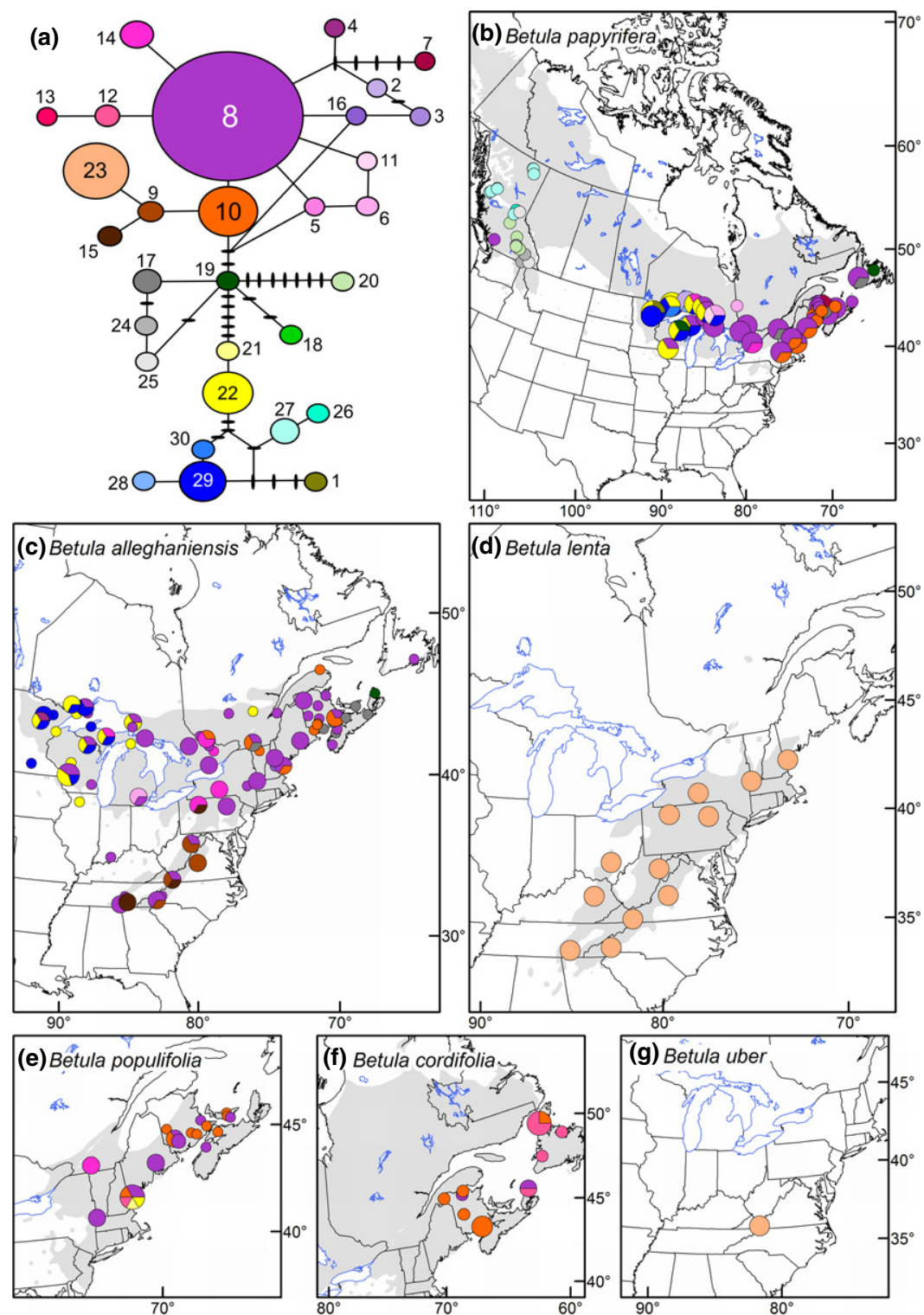

alleghaniensis revealed that haplotype diversity was highest in the central-western Great Lakes region for both species (Fig. 2). There were also areas of moderate diversity located in the Canadian Maritimes range of B. papyrifera and in the Ontario/Quebec range of $B$. alleghaniensis.

\section{Partitioning of molecular variation and phylogeographical structure}

Analyses of molecular variance indicated a significant differentiation in cPSSR haplotype frequencies among populations of B. papyrifera $(56.2 \%)$ and B. alleghaniensis (61.3\%) (Table 1). Population genetic subdivision $\left(G_{\mathrm{ST}}\right)$ was strong in both species, but was somewhat higher for B. alleghaniensis (0.601) than B. papyrifera (0.526). In contrast, B. lenta did not demonstrate variation within or among populations. $R_{\mathrm{ST}}$ was significantly higher than $G_{\mathrm{ST}}$ in $B$. papyrifera
$\left(G_{\mathrm{ST}}=0.526, R_{\mathrm{ST}}=0.691, P<0.05\right)$ and $B$. alleghaniensis $\left(G_{\mathrm{ST}}=0.601, R_{\mathrm{ST}}=0.725, P<0.05\right)$ indicating the presence of a phylogeographical structure in both species.

Marginal log-likelihood values and fixation indices obtained from the spatial and non-spatial BAPS analysis are available from the authors upon request. Spatial Bayesian clustering analysis of the combined cpSSR and $p s b \mathrm{~A}-t r n \mathrm{H}$ dataset revealed the optimal group structure for B. papyrifera when populations were grouped into five clusters (corresponding $F_{\mathrm{CT}}=0.686$ ). The largest group (group 1) was composed of populations occupying the eastern range of $B$. papyrifera, from New England and the Maritimes to the central Great Lakes region, and included a single disjunct population from southern British Columbia (Fig. 3a). Groups 2 and 3 were smaller and included populations from the central Great Lakes region and western Great Lakes region, respectively, while groups 4 and 5 included southern and 

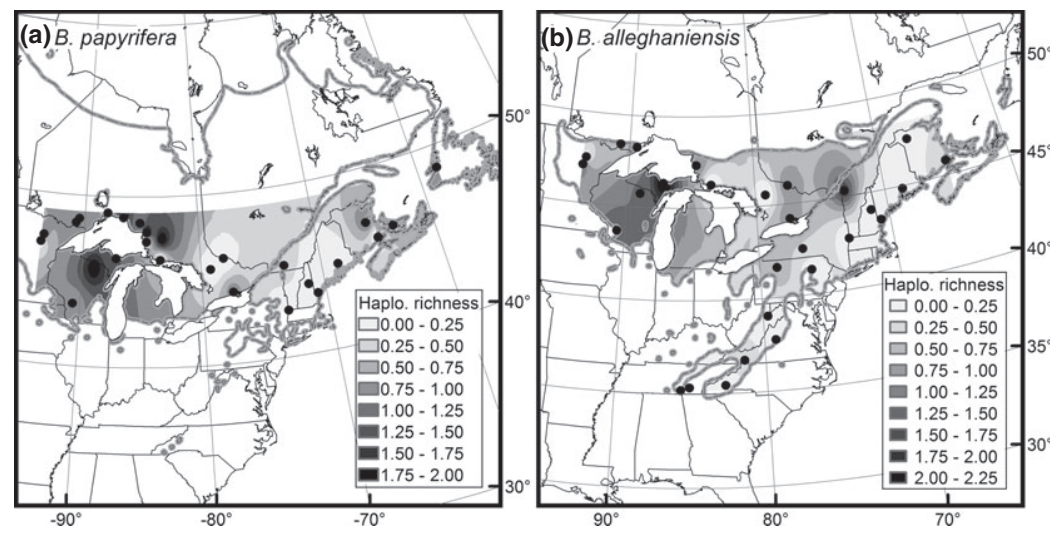

Figure 2 Mapped chloroplast microsatellite (cpSSR) haplotype richness for eastern North American populations of (a) Betula papyrifera and (b) B. alleghaniensis. Values were determined by interpolation of haplotype richness values for individual sampled populations using ArcGIS. Only those populations with a minimum of three sampled individuals were included in the analysis. The interpolated grid is clipped to the extent of the sampled populations to avoid extrapolation outside the study area. Other species were not analysed because they did not demonstrate cPSSR variation or because sample sizes were not sufficient.

Table 1 Analysis of molecular variance (AMOVA) and tests of phylogeographical structure ( $R_{\mathrm{ST}}$ versus $\left.G_{\mathrm{ST}}\right)$ for eastern North American Betula papyrifera and B. alleghaniensis based on chloroplast microsatellite (cpSSR) markers. Only populations with three or more samples were included in the analysis.

\begin{tabular}{llcccccc}
\hline Species & Source of variation & d.f. & Variation (\%) & $P$-value & $G_{\mathrm{ST}}$ & $\begin{array}{c}R_{\mathrm{ST}} \\
P \text {-value }\end{array}$ \\
\hline B. papyrifera & Among populations & 25 & 56.2 & $<0.001$ & 0.526 & 0.691 & 0.012 \\
& Within populations & 196 & 43.8 & & - & - & - \\
B. alleghaniensis & Among populations & 28 & 61.3 & $<0.001$ & 0.601 & 0.725 & $<0.001$ \\
& Within populations & 232 & 38.7 & & - & - \\
\hline
\end{tabular}

$G_{\mathrm{ST}}$, measure of differentiation that makes use only of allelic frequency differences among populations.

$R_{\mathrm{ST}}$, measure of differentiation for which genetic distances as a result of differing microsatellite repeat numbers are taken into account.

$R_{\mathrm{ST}}>G_{\mathrm{ST}}, P$-value for test of phylogeographic structure.

northern British Columbia populations, respectively. For $B$. alleghaniensis the optimal spatial group structure occurred for $K=4$ (corresponding $F_{\mathrm{CT}}=0.764$ ). The largest group (group 1) spanned most of the eastern distribution of B. alleghaniensis from the central Great Lakes region to the western Maritimes, New England, and south to the Appalachians (Fig. 3b). Group 2 was smaller and more regionally restricted, consisting of several populations from the eastern Maritimes, while group 3 included the westernmost B. alleghaniensis populations from the central and western Great Lakes region. In comparison, population clusters identified by BAPs without consideration of spatial reference information resulted in a greater number of population groups for both B. papyrifera $(K=7$; Fig. $3 \mathrm{c})$ and $B$. alleghaniensis $(K=5$; Fig. $3 \mathrm{~d})$ and somewhat differing geographical patterns. Specifically, the non-spatial clustering for B. papyrifera included an additional population group in the north-central Great Lakes region and an additional group in southern British Columbia. For B. alleghaniensis, the non-spatial BAPS analysis recognized Appalachian populations containing endemic haplotypes (H9 and H15) as belonging to a distinct cluster, whereas these populations were not recognized as distinct based on the spatial BAPs analysis.

\section{Partitioning of cpDNA variation among species}

When B. papyrifera, B. alleghaniensis and B. lenta were considered jointly, AMOVA revealed that the majority of cpSSR haplotype variation was partitioned among species (40.7\%), while $35.2 \%$ of the variation occurred among populations within species and $24.1 \%$ of the variation occurred within populations (Table 2). However, variation among the polyploid species $B$. papyrifera and B. alleghaniensis was low $(0.3 \%)$ and non-significant. When B. papyrifera and $B$. alleghaniensis were analysed at the 17 sites at which they co-occurred, a total of eight cpSSR haplotypes was found and five of those were shared between them. The IG ratio calculated for B. papyrifera and B. alleghaniensis across the 17 pooled sites was 0.98 , while IG ratios for individual sites ranged from 0.36 to 1.12 , with an across-site average of 0.89 , indicating that the two species generally had similar haplotype frequencies on sites where they co-occurred (data are available from the authors upon request). Correlations of IGR with geographical distance were significant and negative, indicating the occurrence of isolation-by-distance between populations of $B$. papyrifera and B. alleghaniensis with B. papyrifera as the focal species $(r=-0.458$, 
Figure 3 Geographical groupings from BAPS spatial clustering analysis of eastern North American Betula populations: (a) $B$. papyrifera $\left(K=5, F_{\mathrm{CT}}=0.686\right)$ and (b) $B$. alleghaniensis $\left(K=4, F_{\mathrm{CT}}=0.764\right)$. Geographical groupings from BAPs nonspatial clustering analysis of North American Betula populations: (c) B. papyrifera $\left(K=7, F_{\mathrm{CT}}=0.751\right)$ and (d) $B$. alleghaniensis $\left(K=5, F_{\mathrm{CT}}=0.727\right)$. The geographical range of each species is indicated by light grey shading. Other species were not analysed because they did not demonstrate cPSSR variation or because sample sizes were not sufficient.
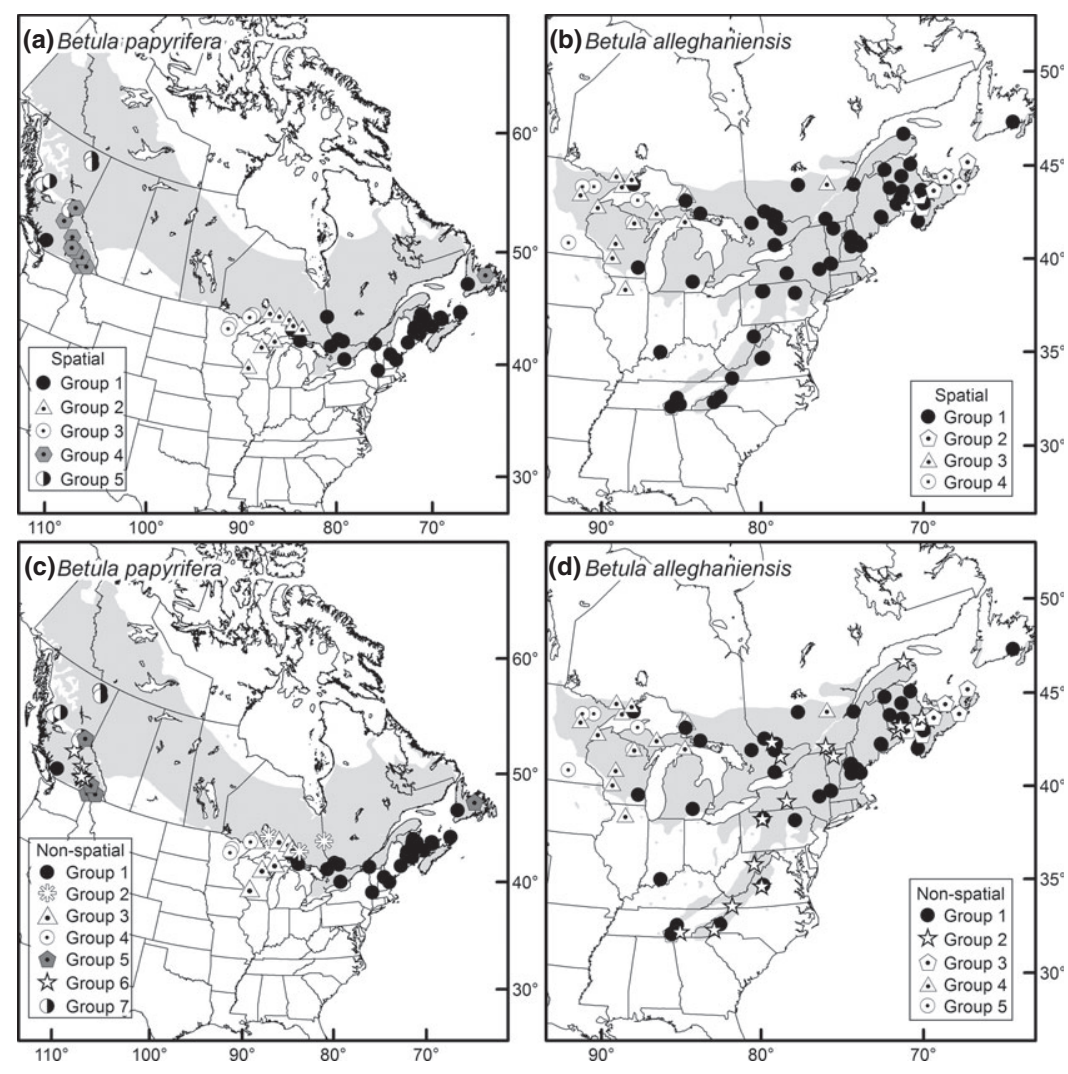

$P<0.001)$ and with $B$. alleghaniensis as the focal species $(r=-0.558, P<0.001)$.

\section{DISCUSSION}

\section{Phylogeographical patterns and Pleistocene biogeography}

This study has revealed generally similar spatial patterns of haplotype variation among species despite some differences in haplotype compositions. Haplotype distributions and вAPS analyses indicated at least three separate glacial lineages for Betula in eastern North America: (1) a large eastern group occurring from the southern Appalachians to New England and the Maritimes, Quebec and eastern Ontario; (2) a western group located in the Great Lakes region; and (3) a geographically restricted eastern group overlapping with the large eastern group along the Atlantic coast of Canada and the northern USA. These groups mostly correspond well with the LGM fossil pollen and macrofossil reconstructions for Betula in eastern North America that indicate the presence of low-density Betula populations in the mid-Atlantic coastal

Table 2 Analysis of molecular variance among eastern North American Betula species based on chloroplast microsatellite (cpSSR) haplotype frequencies. Only populations with three or more samples were included in the analysis.

\begin{tabular}{|c|c|c|c|c|c|}
\hline Species grouping & Source of variation & d.f. & Variation $(\%)$ & Fixation indices & $P$-value \\
\hline \multirow[t]{3}{*}{ B. papyriferal B. alleghaniensis/ B. lenta } & Among species & 2 & 40.7 & $F_{\mathrm{CT}}=0.40710$ & $<0.001$ \\
\hline & Among populations & 64 & 35.2 & $F_{\mathrm{SC}}=0.59289$ & $<0.001$ \\
\hline & Within populations & 536 & 24.1 & $F_{\mathrm{ST}}=0.75862$ & $<0.001$ \\
\hline \multirow[t]{3}{*}{ B. papyriferal B. alleghaniensis } & Among species & 1 & 0.3 & $F_{\mathrm{CT}}=0.00324$ & 0.3287 \\
\hline & Among populations & 53 & 58.7 & $F_{\mathrm{SC}}=0.58919$ & $<0.001$ \\
\hline & Within populations & 428 & 41.0 & $F_{\mathrm{ST}}=0.59052$ & $<0.001$ \\
\hline \multirow[t]{3}{*}{ B. papyriferal B. lenta } & Among species & 1 & 61.8 & $F_{\mathrm{CT}}=0.61821$ & $<0.001$ \\
\hline & Among populations & 36 & 21.7 & $F_{\mathrm{SC}}=0.56943$ & $<0.001$ \\
\hline & Within populations & 304 & 16.4 & $F_{\mathrm{ST}}=0.83561$ & $<0.001$ \\
\hline \multirow[t]{3}{*}{ B. alleghaniensis/ B. lenta } & Among species & 1 & 62.3 & $F_{\mathrm{CT}}=0.62250$ & $<0.001$ \\
\hline & Among populations & 39 & 23.4 & $F_{\mathrm{SC}}=0.61842$ & $<0.001$ \\
\hline & Within populations & 340 & 14.4 & $F_{\mathrm{ST}}=0.85595$ & $<0.001$ \\
\hline
\end{tabular}

$F_{\mathrm{CT}}$, differentiation among groups of populations; $F_{\mathrm{SC}}$, differentiation among populations within groups; $F_{\mathrm{ST}}$, differentiation among populations. 
plain, northern Georgia, the Midwest and north-central Louisiana between 18 and 15 ka (Delcourt \& Delcourt, 1987; Jackson et al., 1997, 2000).

One large haplotype group, consisting of $\mathrm{H} 8$ and related haplotypes, predominated across much of the eastern range of B. papyrifera and B. alleghaniensis, and haplotypes of this group were also frequent within sympatric populations of $B$. populifolia and B. cordifolia. This haplotype group corresponds geographically to group 1 identified by BAPs spatial analysis for $B$. alleghaniensis and B. papyrifera, containing populations from the southern Appalachians to New England, the Maritimes and into eastern Ontario. We suggest that this distinct eastern lineage originated from an Appalachian or mid-Atlantic coastal refugium, as fossil pollen and macrofossil reconstructions indicate the presence of Betula populations in the mid-Atlantic coastal plain and southern Appalachia at the time of the LGM (Delcourt \& Delcourt, 1987; Jackson et al., 1997, 2000). In B. alleghaniensis, a group of endemic haplotypes (H9 and H15) was found in the southern Appalachians. These haplotypes have a close phylogenetic relationship with the sympatric and widespread haplotype H8. Populations containing this southern Appalachian haplotype group were not recognized as a distinct cluster based on the spatial BAPs analysis, but were grouped with other populations of mixed haplotype composition in the non-spatial BAPS analysis. Although this pattern could arise from genetic drift, i.e. allele-surfing during post-glacial recolonization (Excoffier et al., 2009), it could indicate that the Appalachian region was colonized from two or more eastern refugial populations, as has been suggested for several co-distributed species, including hemlock (Tsuga canadensis) (Lemieux et al., 2011), Narceus millipedes (Walker et al., 2009) and spotted salamanders (Ambystoma maculatum) (Zamudio \& Savage, 2003). Our analyses identified a distinct western lineage containing haplotypes mostly endemic to the Great Lakes region (H22 and H29). This lineage corresponds geographically with spatial BAPS groups 2 and 3 for B. papyrifera and groups 3 and 4 for $B$. alleghaniensis. The presence of endemic haplotypes within this region suggests that the western lineage recolonized from a distinct refugium located west of the Appalachians. Currently, the refugial origins of this lineage are unclear, as potential western refugial locations fall outside the current distribution of B. papyrifera and $B$. alleghaniensis and representative samples could not be obtained. We postulate that the western lineage may have originated from a Mississippian refugium, or from periglacial refugia in mid-western USA, which have been identified as sources of recolonization of Great Lakes populations of other eastern North American plant species (McLachlan et al., 2005; de Lafontaine et al., 2010; Peirson et al., 2013). Notably, fossil pollen data for Betula suggests the existence of low-density populations in north-central Louisiana at 18,000 yr вр (Delcourt \& Delcourt, 1987) and in the Midwest between 15,000 and 14,000 yr вр (Jackson et al., 1997).

A pair of closely related and regionally restricted cpDNA haplotypes (H17 and H19) was recovered along the Atlantic coastal region in both B. papyrifera and B. alleghaniensis. Populations from that region formed a distinct genetic cluster corresponding to BAPS spatial group 2 for B. alleghaniensis. The presence of these endemic haplotypes suggests that this area may have been populated from a refugium located in or near this area. Although there is little fossil data to support the existence of an Atlantic refugium, endemic haplotypes of jack pine (Pinus banksiana) and black spruce (Picea mariana) have been found within the same area (Jaramillo-Correa et al., 2004, 2009; Godbout et al., 2005; Gérardi et al., 2010). Godbout et al. (2005) suggest that Atlantic populations may have recolonized from a cryptic refugium located on an exposed Atlantic shelf. Together, these studies suggest that a cryptic Atlantic refugium might have harboured low-density populations of Betula and other borealtemperate plant species at the time of the LGM.

Although it is sometimes postulated that recently colonized areas should harbour reduced levels of genetic diversity as a result of founder effects during recolonization (e.g. Hewitt, 2000), in the present study the areas of highest genetic diversity for Betula were observed in previously glaciated areas. Populations of the central-western Great Lakes region harboured the highest levels of genetic diversity for both B. papyrifera and B. alleghaniensis. These populations contained haplotypes characteristic of both the western (H22 and H29) and eastern (H8) lineages, and thus the Great Lakes region appears to represent a zone of biogeographical contact between eastern and western glacial lineages. It is also possible that the diversity of the central-western Great Lakes region may be partially attributable to introgression, considering that this region represents a zone of natural hybridization between B. papyrifera and B. alleghaniensis (Barnes et al., 1974).

\section{Comparison of phylogeographical patterns among species}

Betula papyrifera and B. alleghaniensis both possessed relatively high levels of haplotype diversity and displayed similar phylogeographical patterns within eastern North America. In comparison, B. lenta was the outlier in that it was fixed for a single haplotype and lacked phylogeographical structure. The finding of just one haplotype in B. lenta indicates that the current distribution may derive from a single glacial lineage, which presumably would have originated from the Appalachian region. Thus the low cpDNA diversity of $B$. lenta might be attributed to a restricted LGM range and associated low population size leading to haplotype fixation through genetic drift. Indeed, low levels of cpDNA diversity found in a number of boreal-temperate trees are attributed to small LGM population sizes (Demesure et al., 1996; Echt et al., 1998; Vendramin et al., 2008). In contrast, genetic structure analyses for $B$. papyrifera and $B$. alleghaniensis suggest that these species may derive from at least three separate eastern North American lineages. Thus we suggest that the relatively high haplotype diversity of $B$. papyrifera and B. alleghaniensis 
may be attributed to relatively broad LGM distributions translating into larger population sizes and greater population connectivity in the glacial and post-glacial landscapes.

This study uncovered regionally structured haplotype sharing between $B$. papyrifera and B. alleghaniensis, which also shared haplotypes with $B$. populifolia and $B$. cordifolia throughout their sympatric distribution. Similar patterns of local haplotype sharing have been documented in numerous plant groups and are often attributed to chloroplast capture as a result of historic hybridization and introgression within shared glacial refugia or during post-glacial expansion (e.g. Prentice et al., 2008). Under this scenario, only a few natural hybrids need to become established to have a large impact on species allele frequencies, if hybridization is followed by repeated backcrossing (Rieseberg et al., 1995; Petit et al., 2003b). In the present study, the finding of regionally shared haplotypes among B. papyrifera and B. alleghaniensis might also indicate chloroplast capture as a result of past hybridization and introgression. Other potential sources of haplotype sharing, including shared ancestry and homoplasy, must also be considered, but are unlikely to explain the observed regional haplotype sharing because they are expected to result in a random distribution of shared haplotypes across a geographical range (Palme et al., 2004). In contrast, haplotype sharing as a result of introgression should result in similar haplotype composition among species within geographical regions, as was found for $B$. papyrifera and B. alleghaniensis in this study (IG ratio 0.89). While haplotypes $\mathrm{H} 8$ and $\mathrm{H} 10$ are probably the oldest haplotypes and might therefore be shared through ancestral polymorphism, haplotypes H6, H14 and H19 are less frequent and peripheral, suggesting that they are unlikely to be shared through common ancestry and thus might be shared as a result of introgression. Also, while shared ancestry should result in a widespread distribution of shared haplotypes or shared haplotypes that occur in different geographical regions for different species (Palme et al., 2004), all of the haplotypes shared among Betula species in this study had restricted geographical distributions that were concordant among species (with the exception of H8, which was also found in a single western North American population of B. papyrifera).

Additional evidence suggesting that haplotype sharing might be the result of introgression is the lack of significant differentiation between haplotype frequencies of B. papyrifera and $B$. alleghaniensis, which could suggest a lack of reproductive isolation between the two species. The regression of IGR values against geographical distance revealed significant isolation-bydistance between population pairs of B. papyrifera and B. alleghaniensis, which suggests the occurrence of local gene flow. Moreover, IGR values were on average less than 1 , indicating that haplotype compositions were more strongly influenced by geography than by species identity. Together, these results suggest an important role of introgression in influencing the phylogeographical structure and haplotype sharing of B. papyrifera and $B$. alleghaniensis, similar to that reported for European birches (Palme et al., 2004; Thórsson et al., 2010).
In the Appalachian region, B. lenta and B. uber shared $\mathrm{H} 23$, for which they were both fixed, while B. lenta did not share haplotypes with the remaining Betula species. We suggest that shared ancestry is potentially responsible for the haplotype sharing of $B$. lenta and $B$. uber, as morphological and molecular studies indicate a close phylogenetic relationship between the two species (Sharik \& Ford, 1984; Li et al., 2005) and it has also been suggested that B. uber represents a variant of B. lenta (Sharik, 1990).

Differing ploidy numbers among the Betula species in this study may play a role in influencing patterns of introgression, as differing ploidy levels are expected to act as a major barrier to gene flow among species (Hersch-Green, 2012). In contrast, gene flow is more likely to occur when species have the same number of chromosomes. Thus we expect that the apparent cpDNA introgression observed between B. papyrifera and $B$. alleghaniensis is facilitated by similar chromosome numbers $(B$. papyrifera $=5 \times, 6 \times ; B$. alleghaniensis $=6 \times)$, whereas cpDNA introgression between diploid $B$. lenta and polyploids $B$. alleghaniensis and B. papyrifera could be impeded by different chromosome numbers and associated post-zygotic incompatibilities.

\section{CONCLUSIONS}

The high level of chloroplast haplotype diversity observed in B. papyrifera and B. alleghaniensis in this study could be attributed to their relatively broad LGM distributions translating into relatively large population sizes in the glacial and post-glacial landscape. In contrast, $B$. lenta was fixed for one haplotype, suggesting that a restricted LGM distribution contributed to population bottlenecks. The high haplotype diversity of $B$. papyrifera and B. alleghaniensis of the centralwestern Great Lakes region may be the result of biogeographical contact between eastern and western glacial lineages but introgression could also contribute to the haplotype diversity of this region. Betula papyrifera and B. alleghaniensis shared local haplotypes, suggesting past introgression within glacial refugia or during post-glacial migration, whereas $B$. lenta did not share haplotypes with the polyploid birches. The inclusion of B. populifolia and B. cordifolia revealed that these species also share localized haplotypes with B. papyrifera and $B$. alleghaniensis across their sympatric distribution, while B. uber shared its single haplotype with B. lenta. Such haplotype sharing across multiple co-distributed species suggests that hybridization and introgression within LGM habitats and during post-glacial expansion has probably played an important role in shaping the patterns of phylogeographical structure of eastern North American birches.

\section{ACKNOWLEDGEMENTS}

We thank three anonymous referees for their insightful comments and suggestions for improving the manuscript. We thank the many personnel associated with the state parks, national forests and experimental forests of the eastern United 
States who provided assistance in locating sites, obtaining sample collections and providing directions and lodging for the various field sites visited as part of this study. We thank Fred Huber of the George-Jefferson National Forest for assisting with $B$. uber sampling. We are grateful to Dale Simpson and Bernard Daigle of the CNTSC, as well as Dave Kolotelo of the BCTSC for providing seed collections. We also thank Greg Kowawleski and Paul Bloese of Michigan State University for assistance in obtaining yellow birch provenance samples and Burton Barnes of the University of Michigan, whose expertise regarding eastern North American birches was instrumental in this study. We thank the various organizations that provided funding, including the National Research Council of Canada, who provided support in the form of a Canada Graduate Scholarship and Michael Smith Foreign Study supplement to A.M.T., a Discovery Grant to S.D., and the US National Science Foundation grant (DEB 0640379) to C.W.D. Additional support was provided by Concordia University, the Quebec Centre for Biodiversity Research and the Quebec Fonds de Recherche Nature et Technologies.

\section{REFERENCES}

Barnes, B.V., Dancik, B.P. \& Sharik, T.L. (1974) Natural hybridization of yellow birch and paper birch. Forest Science, 20, 215-221.

Belahbib, N., Pemonge, M.H., Ouassou, A., Sbay, H., Kremer, A. \& Petit, R.J. (2001) Frequent cytoplasmic exchanges between oak species that are not closely related: Quercus suber and Q. ilex in Morocco. Molecular Ecology, 10, 2003-2012.

Bennett, K.D., Tzedakis, P.C. \& Willis, K.J. (1991) Quaternary refugia of north European trees. Journal of Biogeography, 18, 103-115.

Clement, M., Posada, D. \& Crandall, K.A. (2000) TCS: a computer program to estimate gene genealogies. Molecular Ecology, 9, 1657-1659.

Corander, J., Waldmann, P. \& Sillanpää, M.J. (2003) Bayesian analysis of genetic differentiation between populations. Genetics, 163, 367-374.

Corander, J., Waldmann, P., Marttinen, P. \& Sillanpää, M.J. (2004) BAPS 2: enhanced possibilities for the analysis of genetic population structure. Bioinformatics, 20, 2363-2369.

DeJong, P.C. (1993) An introduction to Betula: its morphology, evolution, classification and distribution, with a survey of recent work. Betula: Proceedings of the IDS Betula Symposium (ed. by D. Hunt), pp. 7-18. Richmond, UK.

Delcourt, P.A. \& Delcourt, H.R. (1987) Long-term forest dynamics of the temperate zone: a case study of late-Quaternary forests in eastern North America. Springer-Verlag, New York.

Demesure, B., Comps, B. \& Petit, R.J. (1996) Chloroplast DNA phylogeography of the common beech (Fagus sylvatica L.) in Europe. Evolution, 50, 2515-2520.

Echt, C.S., DeVerno, L.L., Anzidei, M. \& Vendramin, G.G. (1998) Chloroplast microsatellites reveal population genetic diversity in red pine, Pinus resinosa Ait. Molecular Ecology, 7, 307-316.

Erdmann, G.G. (1990) Yellow birch (Betula alleghaniensis Britton). Silvics of North America, Vol. 2, Hardwoods (ed. by R.M. Burns and B.H. Honkola), pp. 133-147. Agriculture Handbook No. 654, United States Department of Agriculture, Washington, DC.

Excoffier, L., Laval, G. \& Schneider, S. (2005) Arlequin ver. 3.0: an integrated software package for population genetics data analysis. Evolutionary Bioinformatics Online, 1, 47-50.

Excoffier, L., Foll, M. \& Petit, R.J. (2009) Genetic consequences of range expansions. Annual Review of Ecology and Systematics, 40, 481-501.

Furlow, J.J. (1990) The genera of Betulaceae in the southeastern United States. Journal of the Arnold Arboretum, 71, 1-67.

Furlow, J.J. (1997) Betulaceae. Flora of North America north of Mexico, Vol. 3 (ed. by Flora of North America Editorial Committee), pp. 507-538. Oxford University Press, New York.

Gérardi, S., Jaramillo-Correa, J.P., Beaulieu, J. \& Bousquet, J. (2010) From glacial refugia to modern populations: new assemblages of organelle genomes generated by differential cytoplasmic gene flow in transcontinental black spruce. Molecular Ecology, 19, 5265-5280.

Godbout, J., Jaramillo-Correa, J.P., Beaulieu, J. \& Bousquet, J. (2005) A mitochondrial DNA minisatellite reveals the postglacial history of jack pine (Pinus banksiana), a broadrange North American conifer. Molecular Ecology, 14, 3497-3512.

Hersch-Green, E.I. (2012) Polyploidy in Indian paintbrush (Castilleja; Orobanchaceae) species shapes but does not prevent gene flow across species boundaries. American Journal of Botany, 99, 1680-1690.

Heuertz, M., Carnevale, S., Fineschi, S., Sebastiani, F., Hausman, J.F., Paule, L. \& Vendramin, G.G. (2006) Chloroplast DNA phylogeography of European ashes, Fraxinus sp. (Oleaceae): roles of hybridization and life history traits. Molecular Ecology, 15, 2131-2140.

Hewitt, G. (2000) The genetic legacy of the Quaternary ice ages. Nature, 405, 907-913.

Jackson, S.T., Overpeck, J.T., Webb, T. III, Keattch, S.E. \& Anderson, K.H. (1997) Mapped plant-macrofossil and pollen records of late Quaternary vegetation change in eastern North America. Quaternary Science Reviews, 16, 1-70.

Jackson, S.T., Webb, R.S., Anderson, K.H., Overpeck, J.T., Webb, T. III, Williams, J.W. \& Hansen, B.C.S. (2000) Vegetation and environment in Eastern North America during the Last Glacial Maximum. Science, 19, 489-508.

Jaramillo-Correa, J.P., Beaulieu, J. \& Bousquet, J. (2004) Variation in mitochondrial DNA reveals multiple distant glacial refugia in black spruce (Picea mariana), a transcontinental North American conifer. Molecular Ecology, 13, 2735-2747.

Jaramillo-Correa, J.P., Beaulieu, J., Khasa, D.P. \& Bousquet, J. (2009) Inferring the past from the present phylogeographic structure of North American forest trees: seeing 
the forest for the genes. Canadian Journal of Forest Research, 39, 286-307.

Jarvinen, P., Palme, A., Morales, L.O., Lannenpaa, M., Keinanen, M., Sopanen, T. \& Lascoux, M. (2004) Phylogenetic relationships of Betula species (Betulaceae) based on nuclear $A D H$ and chloroplast matK sequences. American Journal of Botany, 91, 1834-1845.

de Lafontaine, G., Turgeon, J. \& Payette, S. (2010) Phylogeography of white spruce (Picea glauca) in eastern North America reveals contrasting ecological trajectories. Journal of Biogeography, 37, 741-751.

Lamson, N.I. (1990) Sweet birch (Betula lenta L.). Silvics of North America, Vol. 2, Hardwoods (ed. by R.M. Burns and B.H. Honkola), pp. 148-152. Agriculture Handbook No. 654, United States Department of Agriculture, Washington, DC.

Lemieux, M.J., Beaulieu, J. \& Bousquet, J. (2011) Chloroplast DNA polymorphisms in eastern hemlock: range-wide genogeographic analyses and implications for gene conservation. Canadian Journal of Forest Research, 41, 1047-1059.

Li, J., Shoup, S. \& Chen, Z. (2005) Phylogenetics of Betula (Betulaceae) inferred from sequences of nuclear ribosomal DNA. Rhodora, 107, 69-86.

Maliouchenko, O., Palmé, A.E., Buonamici, A., Vendramin, G.G. \& Lascoux, M. (2007) Comparative phylogeography and population structure of European Betula species, with particular focus on B. pendula and B. pubescens. Journal of Biogeography, 34, 1601-1610.

McLachlan, J.S., Clark, J.S. \& Manos, P.S. (2005) Molecular indicators of tree migration capacity under rapid climate change. Ecology, 86, 2088-2098.

Palme, A.E., Su, Q., Palsson, S. \& Lascoux, M. (2004) Extensive sharing of chloroplast haplotypes among European birches indicates hybridization among Betula pendula, $B$. pubescens and B. nana. Molecular Ecology, 13, 167-178.

Parducci, L., Jørgensen, T., Tollefsrud, M.M. et al. (2012) Glacial survival of boreal trees in northern Scandinavia. Science, 335, 1083-1086.

Peakall, R. \& Smouse, P.E. (2006) Genalex 6: genetic analysis in Excel. Population genetic software for teaching and research. Molecular Ecology Notes, 6, 288-295.

Peirson, J.A., Dick, C.W. \& Reznicek, A.A. (2013) Phylogeography and polyploid evolution of North American goldenrods (Solidago subsect. Humiles, Asteraceae). Journal of Biogeography, 40, 1887-1898.

Petit, R.J., Kremer, A. \& Wagner, D.B. (1993) Geographic structure of chloroplast DNA polymorphisms in European oaks. Theoretical and Applied Genetics, 87, 122-128.

Petit, R.J., El Mousadik, A. \& Pons, O. (1998) Identifying populations for conservation on the basis of genetic markers. Conservation Biology, 12, 844-855.

Petit, R.J., Aguinagalde, I., de Beaulieu, J.-L., Bittkau, C., Brewer, S., Cheddadi, R., Ennos, R., Fineschi, S., Grivet, D., Lascoux, M., Mohanty, A., Muller-Starck, G., Demesure-Musch, B., Palme, A., Martin, J.P., Rendell, S. \& Vendramin, G.G. (2003a) Glacial refugia: hotspots but not melting pots of genetic diversity. Science, 1563, 15631565.

Petit, R.J., Bodenes, C., Ducousso, A., Roussel, G. \& Kremer, A. (2003b) Hybridization as a mechanism of invasion in oaks. New Phytologist, 161, 151-164.

Pons, O. \& Petit, R.J. (1996) Measuring and testing genetic differentiation with ordered versus unordered alleles. Genetics, 144, 1237-1245.

Premoli, A.C., Mathiasen, P., Acosta, M.C. \& Ramos, V.A. (2012) Phylogeographically concordant chloroplast DNA divergence in sympatric Nothofagus s.s. How deep can it be? New Phytologist, 193, 261-275.

Prentice, H.C., Malm, J.U. \& Hathaway, L. (2008) Chloroplast DNA variation in the European herb Silene dioica (red campion): postglacial migration and interspecific introgression. Plant Systematics and Evolution, 272, 23-37.

R Core Team (2012) R: a language and environment for statistical computing. R Foundation for Statistical Computing, Vienna.

Rieseberg, L.H., Desrochers, A.M. \& Youn, S.J. (1995) Interspecific pollen competition as a reproductive barrier between sympatric species of Helianthus (Asteraceae). American Journal of Botany, 82, 515-519.

Saeki, I., Dick, C.W., Barnes, B.V. \& Murakami, N. (2011) Comparative phylogeography of red maple (Acer rubrum L.) and silver maple (Acer saccharinum L.): impacts of habitat specialization, hybridization and glacial history. Journal of Biogeography, 38, 992-1005.

Safford, L.O., Bjorkbom, J.C. \& Zasada, J.C. (1990) Paper birch (Betula papyrifera Marsh.). Silvics of North America, Vol. 2, Hardwoods (ed. by R.M. Burns and B.H. Honkola), pp. 158-171. Agriculture Handbook No. 654, United States Department of Agriculture, Washington, DC.

Sang, T., Crawford, D. \& Stuessy, T.F. (1997) Chloroplast DNA phylogeny, reticulate evolution, and biogeography of Paeonia (Paeoniaceae). American Journal of Botany, 84, 1120-1136.

Schenk, M.F., Thienpont, C.-L., Koopman, W.J.M., Gilissen, L.J.W.J. \& Smulders, M.J.M. (2008) Phylogenetic relationships in Betula (Betulaceae) based on AFLP markers. Tree Genetics \& Genomes, 4, 911-924.

Sharik, T.L. (1990) Virginia round-leaf birch recovery plan. United States Fish and Wildlife Service, Newton Corner, MA.

Sharik, T.L. \& Ford, R.H. (1984) Variation and taxonomy of Betula uber, B. lenta, and B. alleghaniensis. Brittonia, 36, 307-316.

Soltis, D.E., Morris, A.B., McLachlan, J.S., Manos, P.S. \& Soltis, P.S. (2006) Comparative phylogeography of unglaciated eastern North America. Molecular Ecology, 15, 42614293.

Stewart, J.R. \& Lister, A.M. (2001) Cryptic northern refugia and the origins of the modern biota. Trends in Ecology and Evolution, 16, 608-613.

Stewart, J.R., Lister, A.M., Barnes, I. \& Dalén, L. (2010) Refugia revisited: individualistic responses of species in 
space and time. Proceedings of the Royal Society B: Biological Sciences, 277, 661-671.

Taberlet, P., Fumgalli, L., Wust-Saucy, A.-G. \& Cosson, J.-F. (1998) Comparative phylogeography and postglacial colonization routes in Europe. Molecular Ecology, 7, 453464.

Thórsson, A.T., Pálsson, S., Lascoux, M. \& AnamthawatJónsson, K. (2010) Introgression and phylogeography of Betula nana (diploid), B. pubescens (tetraploid) and their triploid hybrids in Iceland inferred from cpDNA haplotype variation. Journal of Biogeography, 37, 2098-2110.

Vendramin, G.G., Fady, B., González-Martínez, S.C., Hu, F.S., Scotti, I., Sebastiani, F., Soto, A. \& Petit, R.J. (2008) Genetically depauperate but widespread: the case of an emblematic Mediterranean pine. Evolution, 62, 680-688.

Walker, M.J., Stockman, A.K., Marek, P.E. \& Bond, J.E. (2009) Pleistocene glacial refugia across the Appalachian Mountains and coastal plain in the millipede genus Narceus: evidence from population genetic, phylogeographic, and paleoclimatic data. BMC Evolutionary Biology, 9, 25.

Weising, K. \& Gardner, R.C. (1999) A set of conserved PCR primers for the analysis of simple sequence repeat polymorphisms in chloroplast genomes of dicotyledonous angiosperms. Genome, 42, 9-19.

Willis, K.J., Rudner, E. \& Sümegi, P. (2000) The full-glacial forests of central and southeastern Europe. Quaternary Research, 53, 203-213.

Zamudio, K.R. \& Savage, W.K. (2003) Historical isolation, range expansion, and secondary contact of two highly divergent mitochondrial lineages in spotted salamanders (Ambystoma maculatum). Evolution, 57, 1631-1652.
Zeng, J., Zou, Y.-P., Bai, J.-Y. \& Zheng, H.-S. (2002) Preparation of total DNA from "recalcitrant plant taxa". Acta Botanica Sinica, 44, 694-697.

\section{SUPPORTING INFORMATION}

Additional Supporting Information may be found in the online version of this article:

Appendix S1 A summary of the life-history traits of six eastern North American Betula species.

Appendix S2 Location information and GenBank accession numbers for the eastern North American Betula population samples.

Appendix S3 Primer information, thermocycling procedures and haplotype definitions.

\section{BIOSKETCH}

Ashley M. Thomson is a post-doctoral research fellow in the Department of Ecology and Evolutionary Biology at the University of Michigan. She is interested in the biogeography, population genetics and patterns of adaptive variation of boreal-temperate trees and the systematics and evolution of the eastern North American birches (Betula, Betulaceae).

Author contributions: A.M.T., C.W.D. and S.D. designed the project; A.M.T. collected and analysed the data; A.M.T. led the writing; and C.W.D. and S.D. contributed to the writing.

Editor: Mark Carine 